\title{
Experimental study of the phase behavior of hydrocarbon fluids in porous media at atmospheric and elevated pressures
}

Regueira, Teresa; Sandoval, Diego R.; Stenby, Erling Halfdan; Yan, Wei

Published in:

PE/AAPG/SEG Unconventional Resources Technology Conference

Link to article, DOI:

10.15530/urtec-2019-534

Publication date:

2019

Document Version

Peer reviewed version

Link back to DTU Orbit

Citation $(A P A)$ :

Regueira, T., Sandoval, D. R., Stenby, E. H., \& Yan, W. (2019). Experimental study of the phase behavior of hydrocarbon fluids in porous media at atmospheric and elevated pressures. In PE/AAPG/SEG Unconventional Resources Technology Conference [URTEC-2019-534-MS] URTec. https://doi.org/10.15530/urtec-2019-534

\section{General rights}

Copyright and moral rights for the publications made accessible in the public portal are retained by the authors and/or other copyright owners and it is a condition of accessing publications that users recognise and abide by the legal requirements associated with these rights.

- Users may download and print one copy of any publication from the public portal for the purpose of private study or research.

- You may not further distribute the material or use it for any profit-making activity or commercial gain

- You may freely distribute the URL identifying the publication in the public portal 


\title{
Experimental Study of the Phase Behavior of Hydrocarbon Fluids in Porous Media at Atmospheric and Elevated Pressures
}

\author{
Teresa Regueira*, Diego R. Sandoval, Erling H. Stenby, Wei Yan; Department of \\ Chemistry, Center for Energy Resources Engineering (CERE), Technical University of \\ Denmark, Kgs. Lyngby, Denmark.
}

\begin{abstract}
Copyright 2019, Unconventional Resources Technology Conference (URTeC) DOI 10.15530/urtec-2019-534
This paper was prepared for presentation at the Unconventional Resources Technology Conference held in Denver, Colorado, USA, 22-24 July 2019.

The URTeC Technical Program Committee accepted this presentation on the basis of information contained in an abstract submitted by the author(s). The contents of this paper have not been reviewed by URTeC and URTeC does not warrant the accuracy, reliability, or timeliness of any information herein. All information is the responsibility of, and, is subject to corrections by the author(s). Any person or entity that relies on any information obtained from this paper does so at their own risk. The information herein does not necessarily reflect any position of URTeC. Any reproduction, distribution, or storage of any part of this paper by anyone other than the author without the written consent of URTeC is prohibited.
\end{abstract}

\begin{abstract}
Confinement by tight pores can influence fluid phase behaviour according to some recent investigations. Most of these studies are theoretical and the experimental investigations are relatively scarce. In this work, we have employed the calorimetric approach to study the equilibrium of n-alkanes confined in two synthetic porous materials with a narrow pore size distribution, not only at atmospheric conditions but also at elevated pressures. In addition, we also measured two chalk samples from the Danish North Sea in order to shed light on whether the tight chalk formation will influence the phase behaviour. A shift in the saturation temperature of the confined fluids was observed when confined in the synthetic porous materials, whereas no temperature shift was observed in the fluid confined in the chalk powders. By using phase equilibrium calculation incorporating capillary pressure difference between the gas and liquid phases, we also predicted the temperature shifts and compared them with the experimental values.
\end{abstract}

\section{Introduction}

The influence of porous media on phase behaviour is a topic discussed in the oil industries for decades with revived interests and investigations in recent years due to its potential impact on production from tight shale. For the tight chalk formation in the North Sea, a similar question on the role of porous media in phase behaviour has been frequently asked. Some recent experimental and modelling methods developed for shale may help answer the question.

The Lower Cretaceous chalks in the Danish Central Graben have porosities in the range from 15 to $45 \%$ with a very small average permeability, lower than $1 \mathrm{mD}$. The current production from these reservoir rocks in the Danish Central Graben happens in the Valdemar field, which is a very complex and heterogeneous reservoir with a low and uneven production (Jakobsen et al. 2005). It is expected that in this tight rock the reservoir fluids are subjected to a high degree of confinement. The interaction between the fluid and the pore wall is significant, and there is always a question whether the phase behaviour in the tight formation will be dramatically changed. In principle, the phase behavior of confined fluid can be altered due to large capillary pressure differences, selective adsorption, and extreme reduction in the free space of movement. These effects result in changes of fluid physical properties and shifts in saturation 
pressures/temperatures. When such differences are taken into account into reservoir simulation studies, well performance, gas-oil ratio, oil and gas production rate, and ultimate recovery may be affected. (Wang et al. 2014, Teklu et al. 2014, Dong et al. 2016, Firincioglu et al. 2012)

For the Lower Cretaceous chalk, the dominant confinement effect is supposed to be capillary pressure. However, the extent of the influence needs to be experimentally investigated to quantify the magnitude of this phenomenon and to validate theoretical models used in reserve estimation and production forecast.

Compared with the thereotical analyses, the experimental studies on the confinement effects on phase behaviour are scarce because the conventional PVT cannot be directly applied. These experimental techniques are also very diverse, including temperature-programmed desorption, neutron diffraction, Xray diffraction, volumetric measurements, microfluidic and nanofluidic observations, NMR, and differential scanning calorimetry (DSC), as recently reported by Luo et al. (Luo et al. 2019). The determination of boiling points through DSC is based on the analysis of the boiling thermogram, and it has been previously used to determine the vapour pressure of different bulk fluids, as reviewed by Siitsman and Oja (Siitsman and Oja 2015). Concerning the use of this technique to determine the bubble point of oil related systems under confinement, it is worthwhile to mention the previous studies by Luo et al. (Luo et al. 2015, 2016a, Luo et al. 2016b, Luo et al. 2018, 2019). They reported experimental data of $\mathrm{n}$-alkanes and their binary mixtures confined in different synthetic porous materials with narrow pore size distribution, as well as in mixtures of different porous materials mimicking the pore size distribution of shale. The studies by Deo and coworkers should also be mentioned (Pathak et al. 2017a, Pathak et al. 2017b, Pathak et al. 2017c, Cho et al. 2018), where the vapour liquid equilibria of oil related fluids in silica mesoporous monoliths and kerogen were measured.

In this work we employed the calorimetric method similar to Luo et al. (Luo et al. 2016a) to study the confinement effects and extended it to elevated pressures. A differential heat flux calorimeter was used to determine the vapor liquid equilibria of n-hexane, n-octane, $n$-decane in two synthetic porous materials (silica gel and SBA-15), which have a narrow pore size distribution, as well as in two reservoir chalk powders. The chalk rocks are from the Danish Central Basin, one of them is a chalk from the Ekofisk formation in the Gorm field, whereas the other is a chalk from the Tuxen formation in the Valdemar field. The pore size distribution of the different porous materials was characterized through nitrogen sorption isotherms and mercury intrusion porosimetry. The calorimetric measurements were performed at ambient pressure for n-octane and n-decane confined in the four mentioned porous materials, whereas for nhexane confined in silica gel, the measurements were performed at pressures from (10 to $30 \mathrm{bar}$ ).

We also predicted the shift in saturation conditions with phase equilibrium calculations incorporating the capillary pressure difference between the gas and liquid phases. The Peng-Robinson EoS was employed for modelling the fluid properties and the procedure proposed by Sandoval et al. (Sandoval et al. 2016) for phase envelope calculations was used. A comparison between the measured and the predicted temperature shifts in the boiling points among the bulk and the confined fluids is provided.

\section{Methods}

\section{Experimental procedure}

The materials used in this study were n-hexane, n-octane and n-decane, provided by Sigma-Aldrich, with mole fraction purities given by the manufacturer of $99.2 \%, 99.5 \%$, and $99.4 \%$, respectively. The porous materials used in this work were two synthetic porous materials from Sigma-Aldrich, silica gel Davisil Grade 643 and silica mesoporous SBA-15. Moreover, powder of two reservoir rocks was also used as porous material, one of the rocks is chalk from the Ekofisk formation in the Gorm field, whereas the other one is chalk from the Tuxen formation in the Valdemar field (see Figure 1), both of them from the Danish Central Graben. Rock samples were cleaned by using alternating flow of toluene followed by methanol through the rock sample until obtaining a clean effluent. After, the rock was ground by using a mortar and 
then sieved to a particle size lower than $125 \mu \mathrm{m}$. The obtained rock powder was again cleaned with toluene and methanol by using a Soxhlet apparatus and finally the rock powder was dried in oven.

The characterization of all the porous materials was performed by measuring nitrogen sorption isotherms at $-195.8^{\circ} \mathrm{C}$ of the powder samples through a Quantachrome Autosorb-IQ instrument (silica gel and Tuxen chalk) and a Micromeritics ASAP 2020 instrument (SBA-15 and Ekofisk chalk). The surface area was obtained from the multipoint BET (Brunauer-Emmett-Teller theory (Brunauer et al. 1938)), whereas the BJH method (Barrett, Joyner, and Halenda (Barrett et al. 1951)) through the desorption isotherm was used for the determination of the pore volume, average pore size and pore size distribution. In the case of the reservoir rocks, and due to the higher pore sizes, mercury intrusion porosimetry was also carried out by using a Poremaster PM 33-GT-12 apparatus from Quantachrome Instruments. The determinations of the surface areas, pore volumes, average pore sizes and pore size distributions from the raw experimental data were performed though the software provided with the different apparatuses.

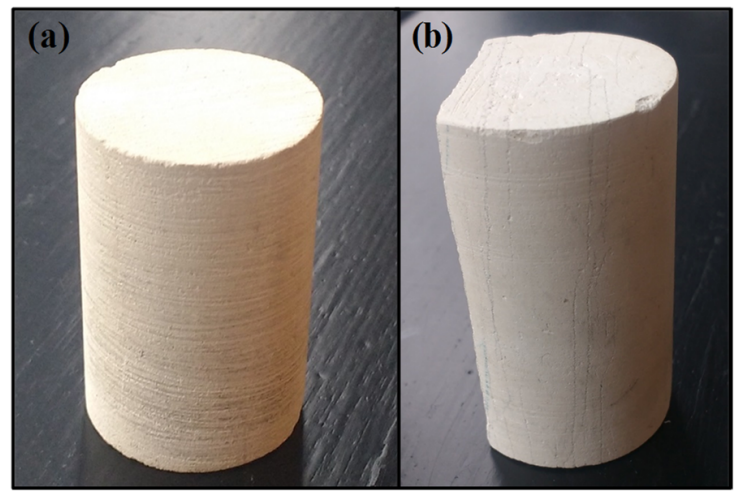

Figure 1. Rock samples used in this work. (a) Ekofisk chalk from Gorm field, (b) Tuxen chalk from Valdemar field.

The measurements of the bubble points of the studied systems were performed by using a differential heat flux calorimeter Setaram C80 at a heating rate of $1{ }^{\circ} \mathrm{C} / \mathrm{min}$. Temperature calibration was performed by determination of the melting points of naphthalene, indium and tin, with a maximum temperature uncertainty of $0.7^{\circ} \mathrm{C}$. Customized calorimetric cells were used with an internal volume of $0.15 \mathrm{~cm}^{3}$. For the measurements at ambient pressure the cells were open to the atmosphere through a $3.18 \mathrm{~mm}$ diameter pipe located in the top of the cell. In the case of the high pressure experiments, this pipe was connected to an injection cylinder containing the sample and a hydraulic fluid separated by a floating piston. The hydraulic fluid side of the injection cylinder was connected to a high pressure pump Teledyne ISCO, which kept the pressure constant during the experiments. The pressure was read and recorded by using a pressure transducer VEGABAR 17, which was calibrated against a reference pressure transducer with an accuracy of 0.25 bar, connected to a data acquisition unit Keysight 34972A. A schematic of the experimental setup can be found elsewhere (Regueira et al. 2017).

The porous material was evacuated for several hours inside a septumed vial prior to the addition of the nalkane, the prepared sample was stirred by using a vortex shaker IKA Vortex Genius 3. Afterwards, a waiting time of 24 hours was applied prior to the transfer of the prepared sample to the calorimetric cell. Both the mass of porous material and $n$-alkane were measured by using a balance Mettler-Toledo PR1203. In the case of n-hexane, the prepared sample was transferred to the calorimetric cell after stirring, then the sample was pressurized with n-hexane by using the ISCO pump and it was kept at constant pressure of 10 bar for several hours prior to the calorimetric measurements. The calorimetric measurements were programed with a constant temperature period before starting with a heating ramp of $1{ }^{\circ} \mathrm{C} / \mathrm{min}$ until a temperature considerably higher than the boiling point was achieved, at this point a period of $2 \mathrm{~h}$ at constant temperature was applied before cooling down the sample to the original temperature. The onset temperatures for the bulk fluid vaporizations were obtained by using the Calisto Processing 
v1.36 software from Setaram. Also isothermal measurements at $162.9^{\circ} \mathrm{C}$ were performed under expansion by using the ISCO pump for $\mathrm{n}$-hexane confined in silica gel.

\section{Modelling}

The modeling of the experimental data was carried out through standard phase equilibrium calculations accounting for a capillary pressure difference between the gas phase and liquid phase. The procedure followed was that suggested by Sandoval et al. (Sandoval et al. 2016) for phase envelope calculations, but instead of tracing the full phase envelope, a single bubble point was calculated here. The Peng-Robinson EoS was used to model the fluid properties and the Young-Laplace equation together with the parachor model was used to model the capillary pressure. The set of equations to solve is as follows,

$$
g\left(T, p^{l}, p^{g}\right)=\left\{\begin{array}{c}
\ln f^{l}\left(p^{l}, T\right)-\ln f^{g}\left(p^{g}, T\right) \\
p^{l}-p^{g}+p_{c a p}
\end{array}=0\right.
$$

where $T$ is the temperature, $f$ is the fugacity, $p^{l}$ and $p^{g}$ are the pressure in the liquid and the gas respectively, and finally $p_{c a p}$ is the capillary pressure which is described as follows,

$$
p_{\text {cap }}=\frac{2 \sigma \cos \theta}{r_{c}}
$$

with

$$
\sigma^{\frac{1}{4}}=\chi\left(\rho^{l}\left(T, p^{l}\right)-\rho^{g}\left(T, p^{g}\right)\right)
$$

where $\sigma$ is the interfacial tension, $r_{c}$ the capillary radius, $\chi$ the parachor constant, and $\rho$ the density of each phase. Here we have assumed full wetting of the liquid phase, or equivalently the fluid-wall contact angle $(\theta)$ is zero. Equation (1) was solved iteratively using a Newton procedure. First, we set the gas pressure $p^{g}$ equal to the measured experimental pressure, and then we solved the remaining two equations in system with respect to $T$ and $p^{l}$.

$$
\left(\begin{array}{c}
T \\
p^{l}
\end{array}\right)^{k+1}=\left(\begin{array}{c}
T \\
p^{l}
\end{array}\right)^{k}-J^{-1} g\left(T, p^{l}\right)
$$

where

$$
J=\left(\begin{array}{cc}
\frac{\partial \ln f^{l}}{\partial T}-\frac{\partial \ln f^{g}}{\partial T} & \frac{\partial \ln f^{l}}{\partial p^{l}} \\
\frac{\partial p_{c a p}}{\partial T} & 1+\frac{\partial p_{c a p}}{\partial p^{l}}
\end{array}\right)
$$

$p^{l}$ is initialized using the same value of $p^{g}$, and $T$ is initialized through Wilson's approximation,

$$
\ln \frac{p^{g}}{p_{c}}=5.373(1+\omega)\left(1-\frac{T_{c}}{T}\right)
$$

where $T_{c}$ is the critical temperature, $p_{c}$ the critical pressure, and $\omega$ is the acentric factor. 


\section{Results and discussion}

\section{Characterization of the porous materials}

Regarding the characterization of the porous materials employed in this work, the obtained nitrogen adsorption-desorption isotherms are depicted in Figure 2, where the volume of nitrogen adsorbed/desorbed at standard conditions is plotted against the relative pressure of nitrogen. It can be observed that both the silica gel and the SBA-15 present hysteresis between the adsorption and desorption branch, which is associated with the capillary condensation characteristic of the mesopore range. However, for the reservoir rock powder samples the hysteresis is absent in the nitrogen sorption isotherms, which indicates negligible amount of mesopores in these rocks, which have a higher average pore diameter.
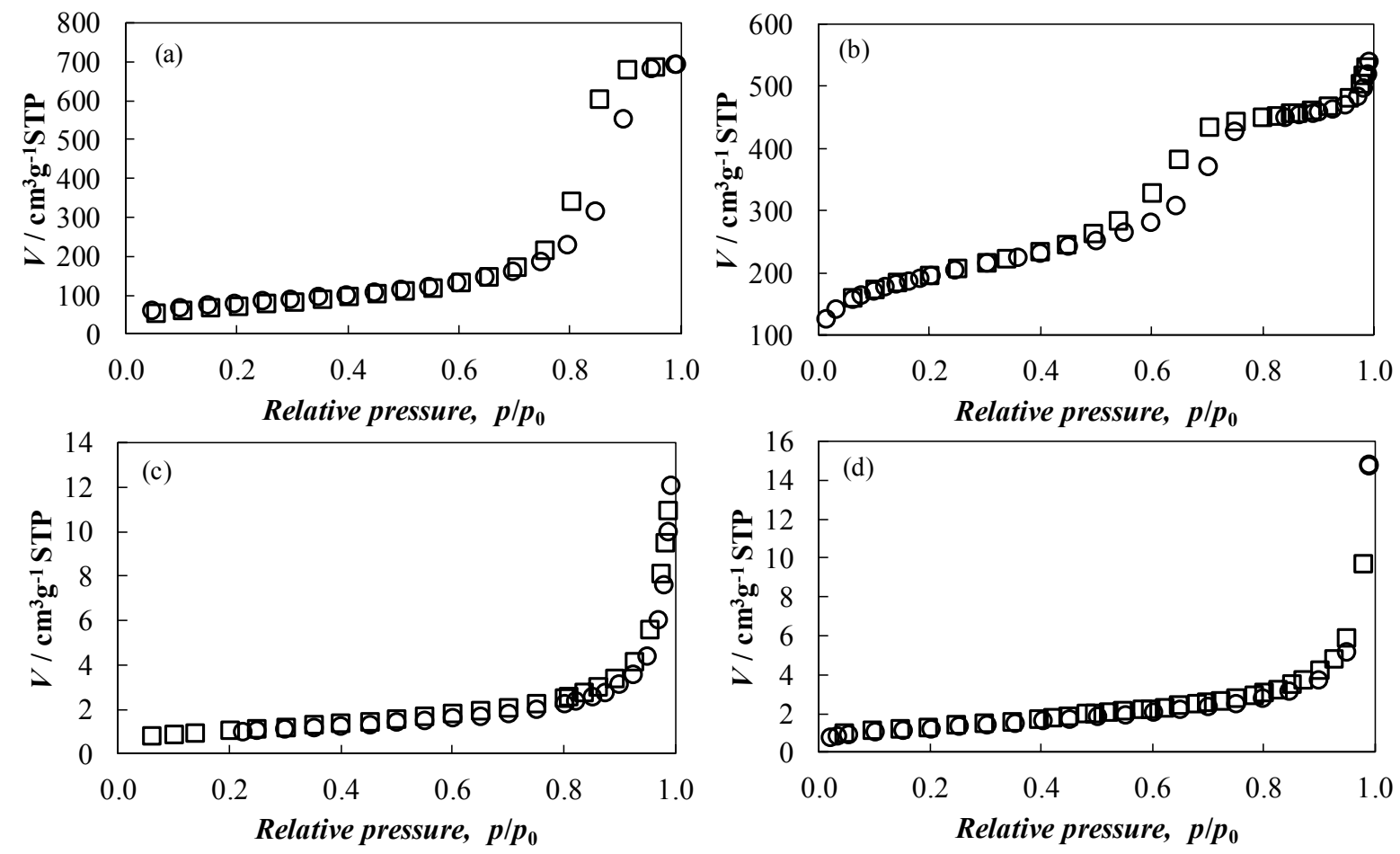

Figure 2. Nitrogen sorption isotherms at $-195.8^{\circ} \mathrm{C}$ on (a) silica gel, (b) SBA-15, (c) Ekofisk chalk Gorm field,

(d) Tuxen chalk Valdemar field. (O) adsorption branch, $(\square)$ desorption branch.

The surface area of the porous materials was determined from the linear part of the plots in Figure 2 up to a relative pressure of 0.4 according to the multipoint BET method (Brunauer et al. 1938). The values of this property are summarized in Table 1 , the synthetic materials present a very high surface area in comparison with that of the chalk samples.

As concerns the pore volume of silica gel and SBA-15, it was obtained from the nitrogen sorption isotherms, whereas those of the chalk samples was obtained from mercury intrusion porosimetry, the results are plotted in the form of cumulative volume in Figure 3, and the numerical values are reported in Table 1. The pore volume of the synthetic materials is much higher than that of the chalk samples.

Finally, the pore size distribution of the studied materials in the mesopore region was obtained by applying the BJH method (Barrett et al. 1951) to the desorption isotherms in Figure 2. As concerns the chalk samples, the pore size distributions and average pore diameters were determined from mercury intrusion porosimetry. The results obtained are presented in Figure 3. It can be seen that the synthetic porous materials present a very narrow pore size distribution with a low average diameter (12.66 and 5.85 
$\mathrm{nm}$ for silica gel and SBA-15, respectively). On the other hand, the rock samples present a broad and bimodal pore size distribution when expressed as $\mathrm{D} V(d)\left(\mathrm{cm}^{3} \mathrm{~nm}^{-1} \mathrm{~g}^{-1}\right)$ as a function of the pore diameter, the average diameter for both chalk samples is similar and around $400 \mathrm{~nm}$, being slightly higher for the Tuxen chalk compared to the Ekofisk chalk. It can also be observed that the volume contribution of the mesopores to the total pore volume of the chalk samples is very small, and that there is a good agreement between the pore volume measured by the nitrogen desorption and the mercury intrusion techniques. It is believed that the influence of the rock crushed on the pore volume determination is small as the particle size is much bigger than the pore size.

Table 1. Characterization results of the porous materials used in this work.

\begin{tabular}{llll}
\hline Material & $\begin{array}{l}\text { Surface area } \\
\mathrm{m}^{2} \mathrm{~g}^{-1}\end{array}$ & $\begin{array}{l}\text { Pore volume } \\
\mathrm{cm}^{3} \mathrm{~g}^{-1}\end{array}$ & $\begin{array}{l}\text { Average pore diameter } \\
\mathrm{nm}\end{array}$ \\
\hline Silica gel & 283.9 & 1.14 & 12.66 \\
SBA-15 & 699.7 & 0.73 & 5.85 \\
Ekofisk chalk Gorm field & 2.65 & 0.27 & 413.28 \\
Tuxen chalk Valdemar field & 1.95 & 0.22 & 444.31 \\
\hline
\end{tabular}
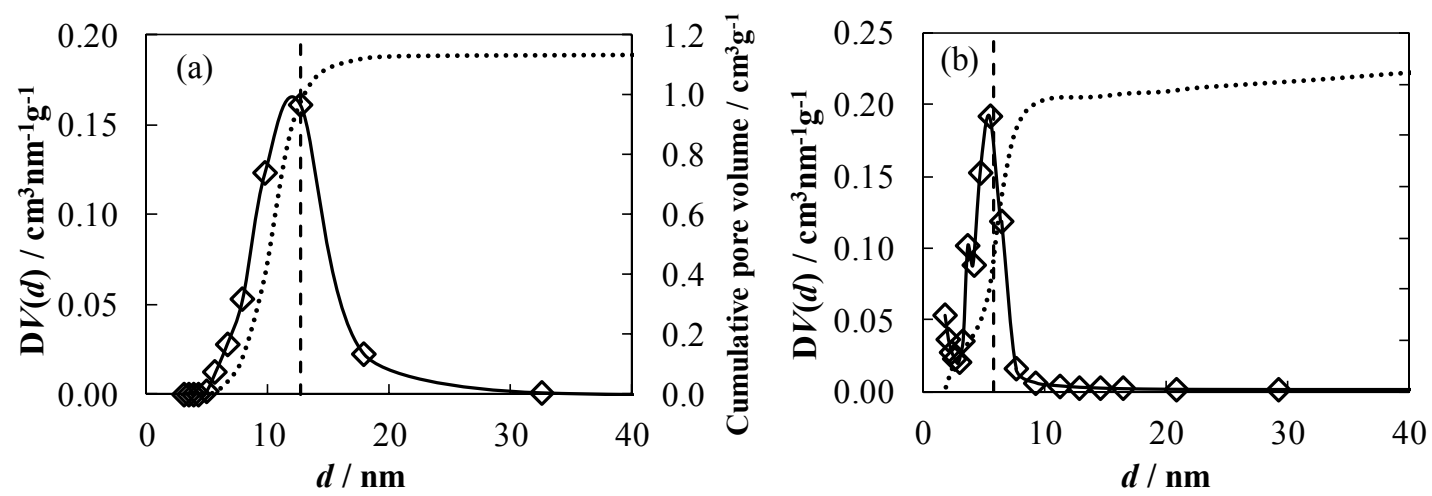

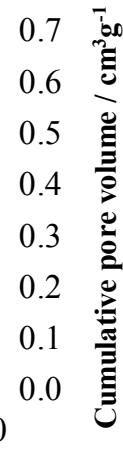
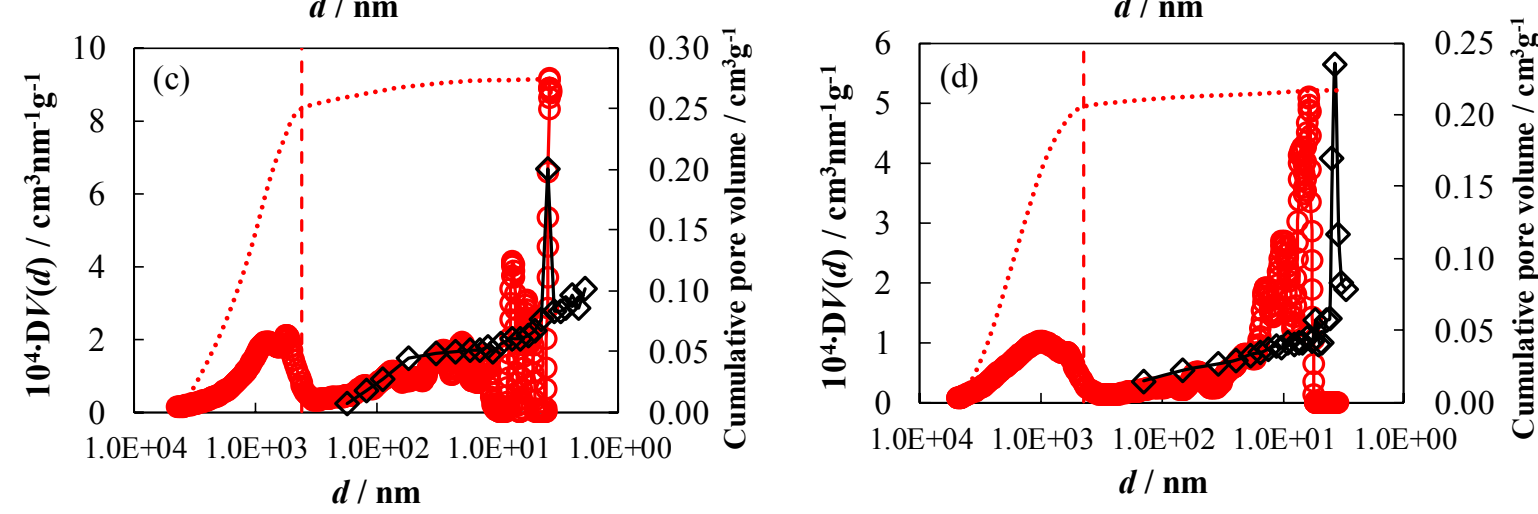

Figure 3. Cumulative pore volume (dotted lines), pore size distribution from nitrogen desorption isotherms $(\diamond)$ and pore throat distribution from mercury intrusion porosimetry (O) for (a) silica gel, (b) SBA-15, (c) Ekofisk chalk Gorm field, (d) Tuxen chalk Valdemar field. The dashed vertical lines represent the average pore diameter.

\section{Experimental determination and modelling of the vapor-liquid equilibrium}

Firstly, it is important to mention that along the present work, a positive heat flow signal represents and endothermic transition in the presented thermograms. 
In order to validate the experimental procedure, the boiling points of bulk fluids n-octane and n-decane at ambient pressure, together with those of n-hexane at 11.4, 19.8 and 29.5 bar were determined. The thermograms for these measurements are presented in Figure 4. The reference boiling points for these nalkanes reported by NIST (REFPROP) (Lemmon et al. 2013, Span and Wagner 2003, Lemmon and Span 2006) are also plotted in Figure 4, where it can be observed a good agreement between the reference boiling temperature and the onset temperature of the vaporization peak. A quantitative comparison of the measured and reference boiling temperatures is reported in Table 2, it can be observed a maximum difference of $1.2^{\circ} \mathrm{C}$ between the experimental and the reference value of the saturation temperature of the bulk fluids, which validates the experimental technique used in this work for determination of vaporliquid equilibrium.
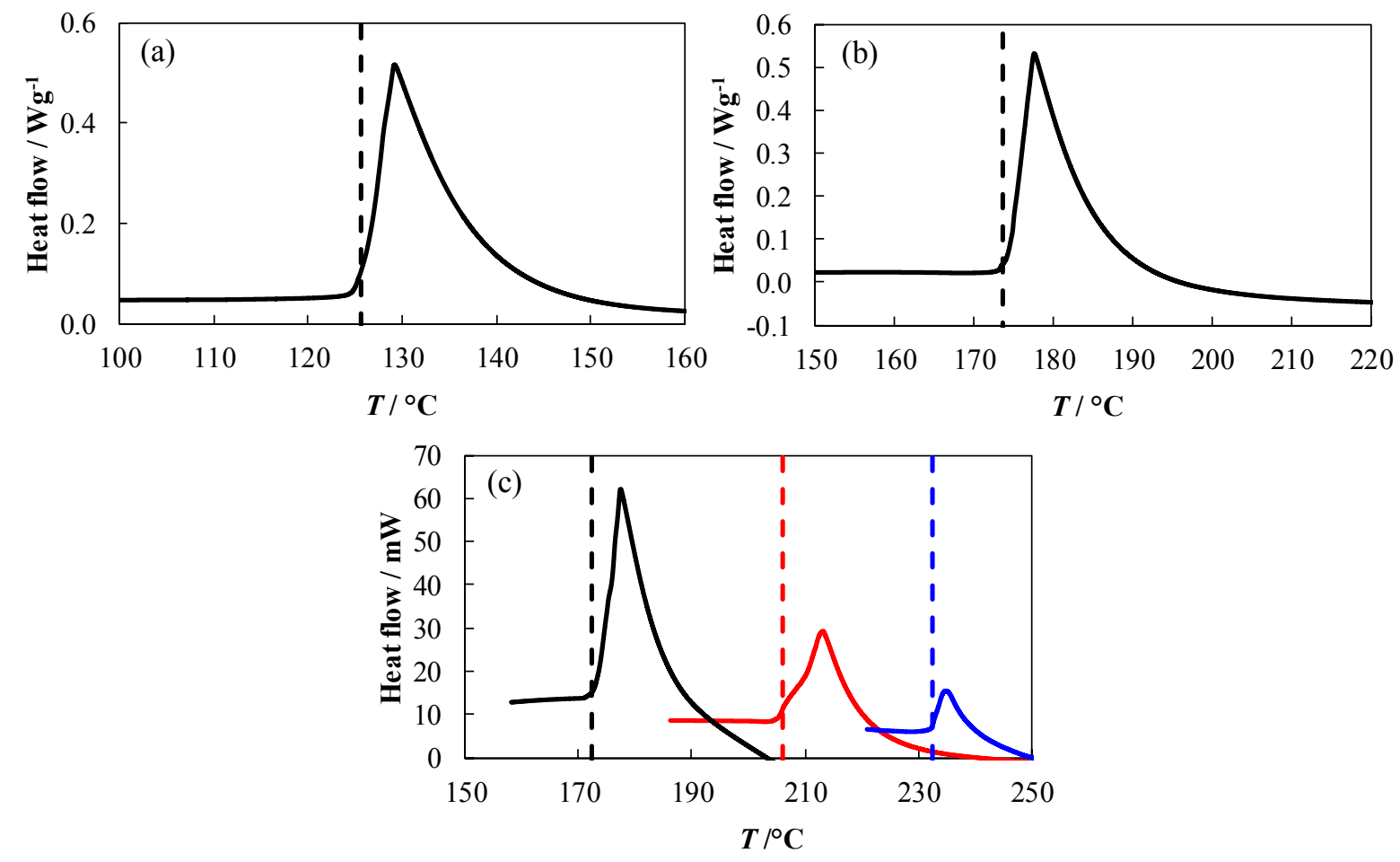

Figure 4. Thermograms of (a) n-octane at 1.02 bar, (b) n-decane at 1.00 bar and (c) n-hexane at 11.4 bar (black line), 19.8 bar (red line) and 29.5 bar (blue line). The dashed lines represent the reference saturation temperature reported by NIST (REFPROP) (Lemmon et al. 2013).

Table 2. Onset temperature ( $T_{\text {onset }}$ ) of the boiling endotherms of the bulk n-alkanes studied in this work.

\begin{tabular}{lllll}
\hline & $p /$ bar & $T_{\text {onset }} /{ }^{\circ} \mathrm{C}$ & $T_{\text {ref }}{ }^{*} /{ }^{\circ} \mathrm{C}$ & $\Delta T^{\ddagger} /{ }^{\circ} \mathrm{C}$ \\
\hline n-octane & 1.02 & 126.2 & 125.79 & 0.4 \\
n-decane & 1.00 & 174.4 & 173.56 & 0.9 \\
n-hexane & 11.4 & 173.2 & 172.32 & 0.8 \\
n-hexane & 19.8 & 204.7 & 205.94 & -1.2 \\
n-hexane & 29.5 & 232.3 & 232.45 & -0.2 \\
\hline
\end{tabular}

${ }^{*}$ Reference saturation temperature given by NIST (REFPROP) (Lemmon et al. 2013, Span and Wagner 2003, Lemmon and Span 2006)

\$Temperature difference between the measured and the reference saturation temperature.

After the determination of the boiling point of the bulk fluids, the measurements were performed for the $\mathrm{n}$-alkanes infiltrated in the different porous materials. In these measurements, the volume of the n-alkane at ambient conditions was in excess compared to the pore volume of the porous material used, so that it 
would be possible to observe in the same thermogram the vaporization of both, the bulk and the confined fluid. The pore loading is defined as the ratio of the volume of the n-alkane at ambient conditions to the pore volume.

The thermograms obtained in the determination of vapor-liquid equilibrium of n-octane and n-decane confined in the different porous materials at ambient pressure are presented in Figures 5 and 6 , respectively. It can be observed that both, the confined n-octane and the n-decane, present two unresolved peaks in the boiling endotherms, when confined in silica gel and in SBA-15. It can be interpreted that the lower temperature peak corresponds to the vaporization of the bulk fluid, whereas the peak at higher temperature corresponds to the vaporization of the fluid confined in the nanopores of the studied material. These results are in agreement with the Kelvin equation. For the n-alkane confined in SBA-15, the confined peak is shifted to higher temperatures due to the higher degree of confinement, as the pore diameter of this material is smaller than the one of silica gel (see Table 1).

On the other hand, in the case of n-octane and n-decane confined in the reservoir rocks, only one peak was observed in the boiling thermogram. This peak occurs at the same temperature as the vaporization of the bulk fluid, which indicates that the effect of confinement is not modifying the temperature of the phase transition, as the average pore size of these materials (around $400 \mathrm{~nm}$ ) is much higher than those of the synthetic porous materials (silica gel and SBA-15). It is worth noting that the shape of the thermograms obtained for n-octane and n-decane confined in the synthetic porous materials is similar to those previously presented by Luo et al. (Luo et al. 2016a) for the same n-alkanes confined in porous materials of similar pore sizes.
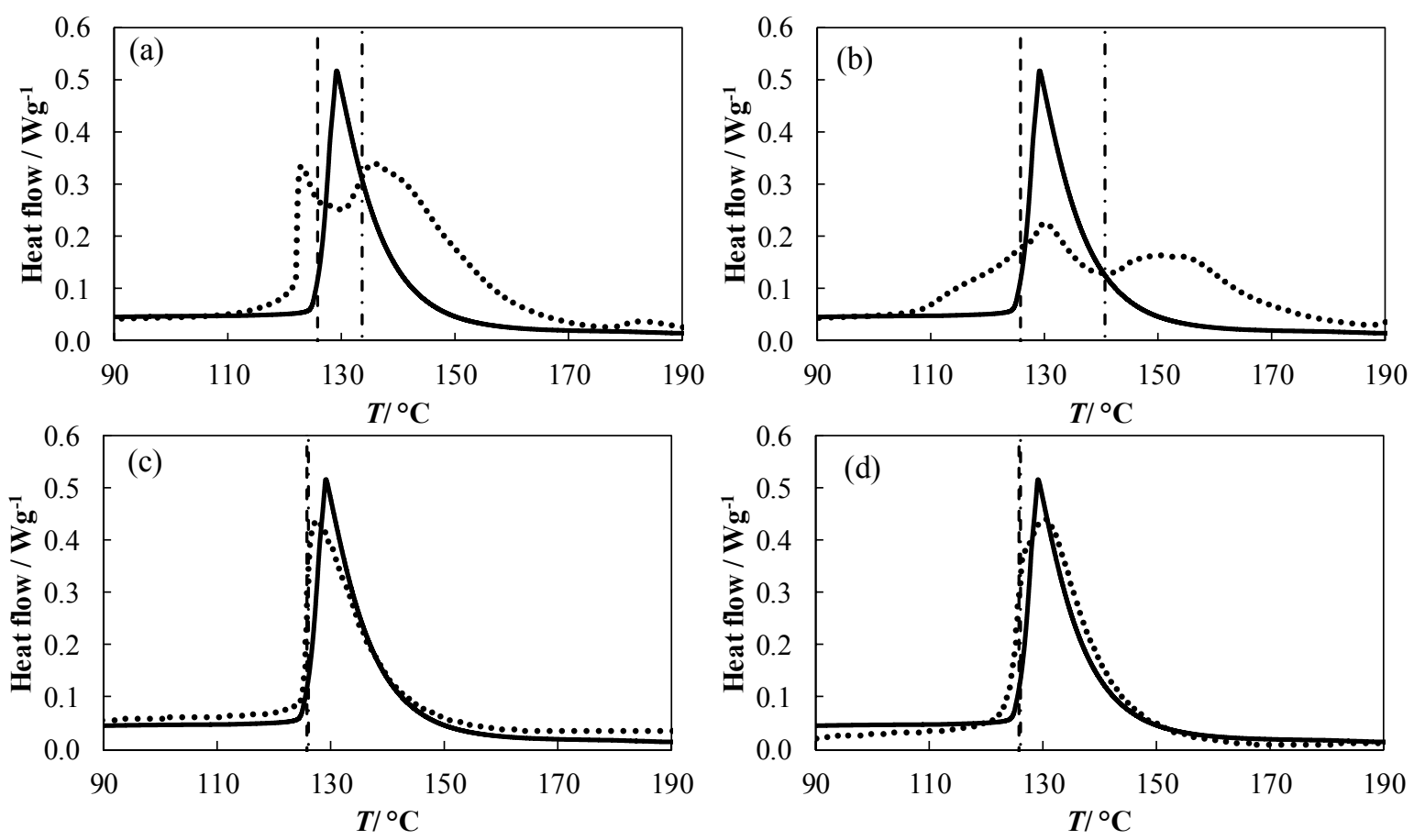

Figure 5. Thermograms for bulk n-octane (solid line) and n-octane overfilled in different porous materials (dotted line) at ambient pressure. (a) Silica gel (369\%), (b) SBA-15 (469\%), (c) Ekofisk chalk Gorm field (255\%), (d) Tuxen chalk Valdemar field (133\%). The dashed and the dasheddotted vertical lines represent the model predictions for the bulk fluid and the confined fluid, respectively. The numbers in brackets represent the loading. 

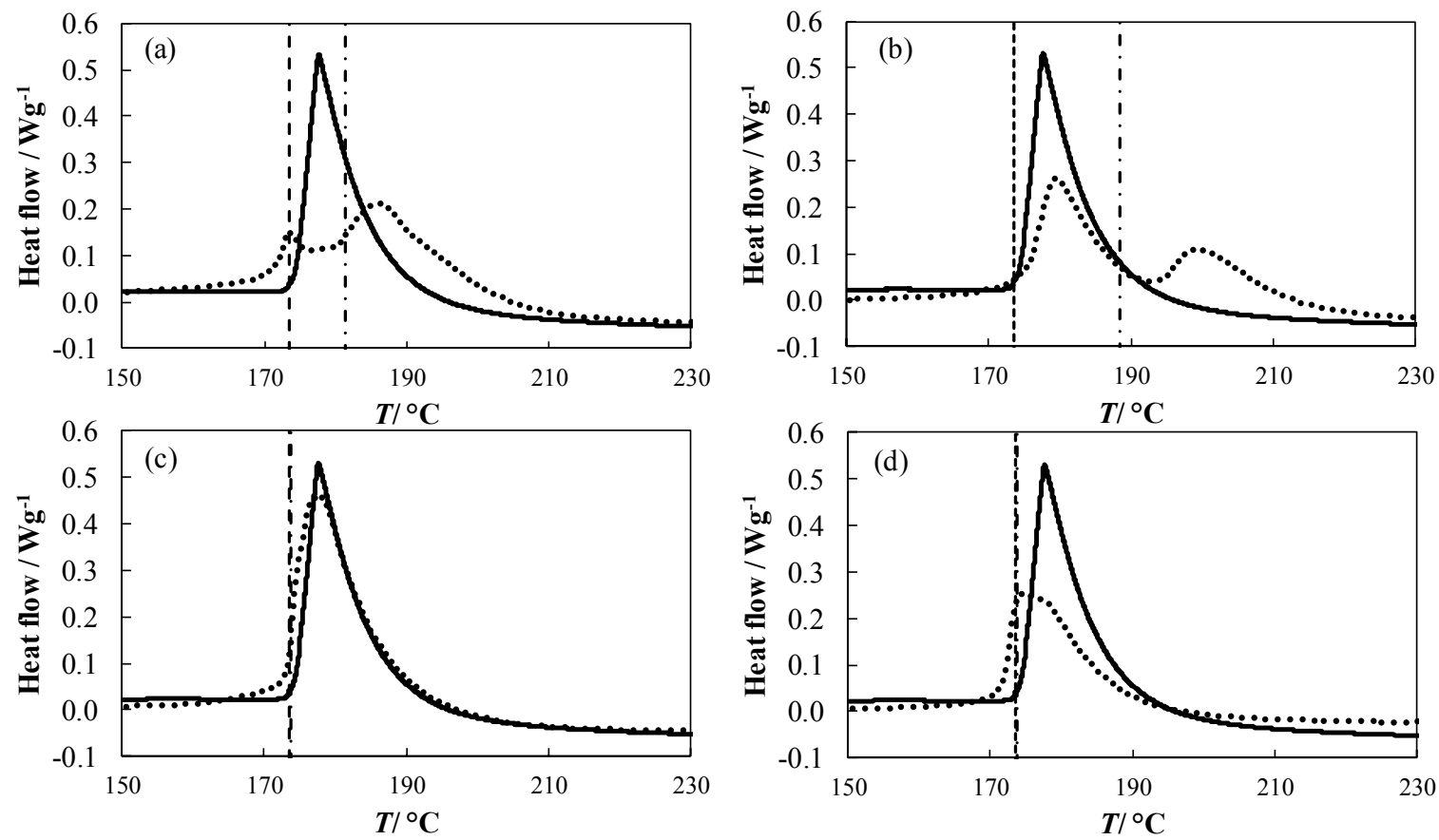

Figure 6. Thermograms for bulk n-decane (solid line) and n-decane overfilled in different porous materials (dotted line) at ambient pressure. (a) Silica gel (168\%), (b) SBA-15 (439\%), (c) Ekofisk chalk Gorm field (117\%), (d) Tuxen chalk Valdemar field (166\%). The dashed and the dasheddotted vertical lines represent the model predictions for the bulk fluid and the confined fluid, respectively. The numbers in brackets represent the loading.

As concerns the determination of the vapor-liquid equilibrium of $n$-hexane at higher pressures confined in the overfilled silica gel, the thermograms obtained can be observed in Figure 7. For the three pressures studied, two unresolved peaks were measured for the n-hexane infiltrated in the porous materials, indicating a vaporization of the bulk fluid at a lower temperature than the vaporization of the confined fluid. The peak separation increases with pressure, this fact is unexpected, as with pressure increase the boiling temperature approaches the critical temperature of $n$-hexane and the difference between the boiling point of the bulk and the confined fluid is expected to be smaller if it is due to the capillary pressure only. It is therefore suspected that the separation of peaks may not be due to capillary pressure only, but also other fluid-wall interaction such as adsorption or some dynamic effects. More investigations are suggested to study this phenomenon.

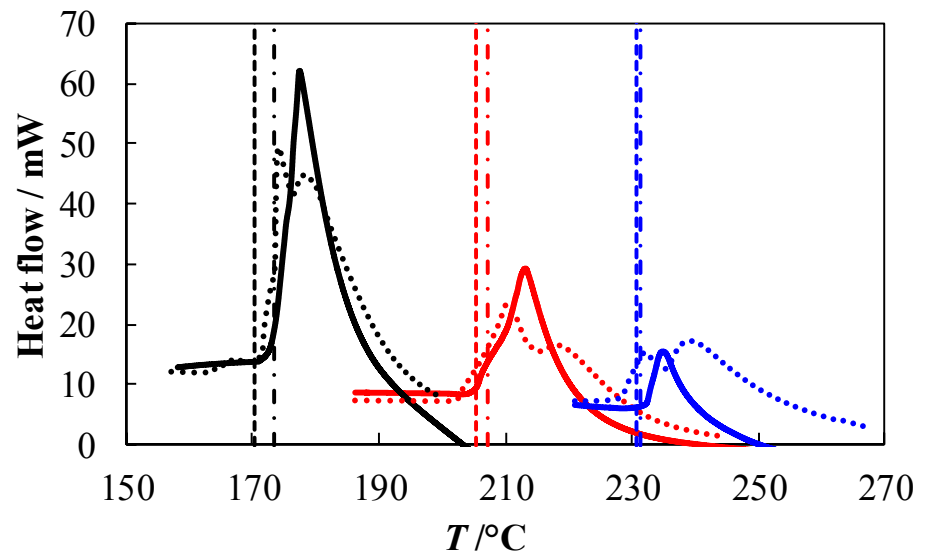

Figure 7. Thermograms for bulk n-hexane (solid line) at 11.4 bar (black), 19.8 bar (red) and 29.5 bar (blue) and n-hexane overfilled in silica gel (dotted line) at 10.8 bar (black), 19.7 bar (red) and 28.9 bar (blue). The vertical dashed and dotted-dashed lines represent the model predictions for the bulk fluid and the confined fluid respectively. 
In order to quantify the experimental shift of phase transition due to confinement, the temperature difference between the two maxima of the peaks instead of the difference of the onset temperatures in the thermograms was analyzed. This approach is particularly convenient since the width of the peaks may overlap and data separation of the peaks is not entirely trivial. These temperature shifts were compared with the model predictions in Figure 8. It can be observed that the temperature shifts obtained experimentally in this work are similar both for n-octane and n-decane when confined in the same porous material, however these temperature shifts are under predicted $\left(5\right.$ to $\left.6^{\circ} \mathrm{C}\right)$ by the model calculations. The temperature shift previously reported for these two n-alkanes in similar porous materials (Luo et al. 2019) is also plotted in Figure 8, and it is smaller than the one measured in this work and higher than model predictions. It should be noticed that the average pore diameter reported by these authors is slightly lower than the one used in this work. Moreover, the fact that the temperature shift is measured at the maxima of the boiling endotherms and not at the onset temperature might introduce differences in the comparison with the literature data, as the broadness of the peak is affected by the heating rate used as well as the sample amount. As concerns the temperature shift measured for n-hexane confined in silica gel at different pressures, it can be observed that there is a good agreement with model predictions at 11 bar, but as pressure increases the model predicts a decrease in the temperature shift, whereas an increase from 11 to 20 bar was observed experimentally. This fact requires further investigations, as effects such as adsorption or the configuration of the experimental setup should be further studied. The results of the calculations of the vapor-liquid equilibria for the different $n$-alkanes and porous materials are gathered in Table 3.
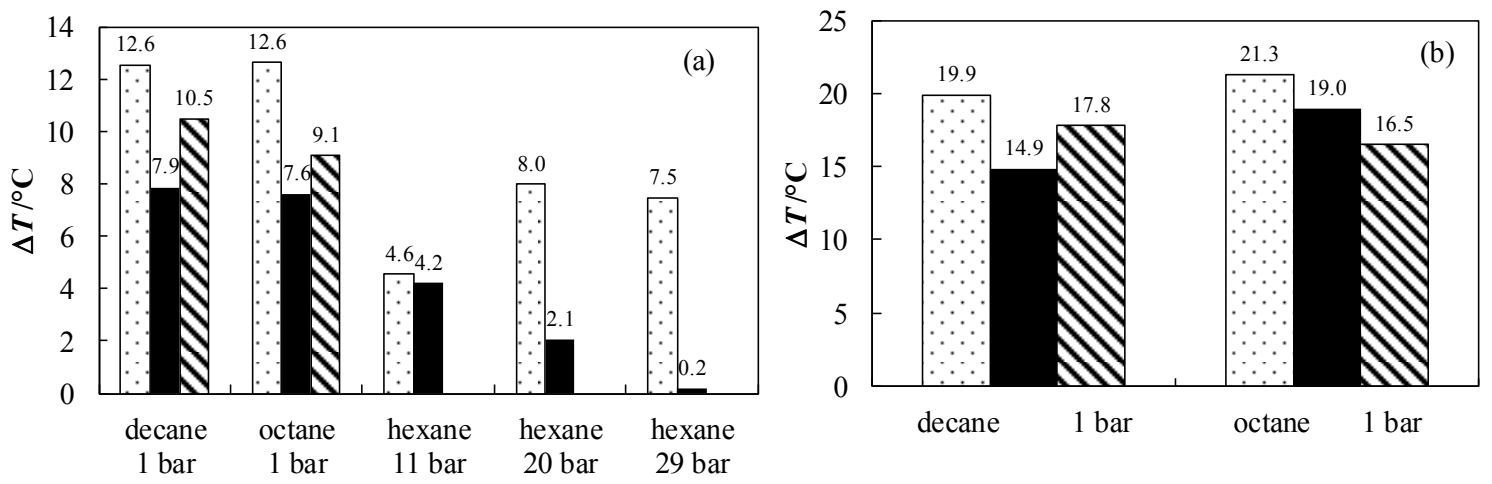

Figure 8. Temperature shift between the saturation temperature of the bulk and the confined fluid in (a) silica gel and (b) SBA-15. This work experimental (dotted), this work calculated (solid), Luo et al. (14.8 nm (a) and $6 \mathrm{~nm}$ (b)) (Luo et al. 2019) (stripped).

Table 3. Calculations of the saturation temperatures for the different n-alkanes and porous materials in ${ }^{\circ} \mathrm{C}$.

\begin{tabular}{lcccccc}
\hline Component & $p$ /bar & bulk & silica gel & SBA-15 & Ekofisk chalk & Tuxen chalk \\
\hline n-octane & 1.018 & 125.82 & 133.65 & 140.6 & 126.13 & 126.11 \\
n-decane & 0.999 & 173.54 & 181.42 & 188.41 & 173.8 & 173.78 \\
n-hexane & 10.8 & 169.17 & 173.38 & 176.54 & -- & -- \\
n-hexane & 19.7 & 205.17 & 207.23 & 208.6 & -- & - \\
n-hexane & 28.9 & 231.18 & 231.36 & 231.42 & -- & - \\
n-hexane & 8.8 & -- & 162.88 & -- & -- & -- \\
n-hexane & 9.6 & 162.88 & -- & -- & -- & -- \\
\hline
\end{tabular}

Finally, an isothermal calorimetric test with decreasing pressure at constant flow rate of $0.02 \mathrm{~cm}^{3} / \mathrm{min}$ was performed at constant temperature of $162.9^{\circ} \mathrm{C}$ for both n-hexane and $\mathrm{n}$-hexane infiltrated in silica gel. The obtained thermograms are presented in Figure 9. It can be observed that the vaporization of the bulk 
fluid happens at constant pressure until the maximum of the peak is reached, in the presence of silica gel two unresolved peaks were measured in the isothermal thermogram. A pressure depression of 2.1 bar due to confinement was determined as the difference between the two maxima in Figure 9 (b), whereas the pressure depression calculated with the model for the same conditions was 0.8 bar.
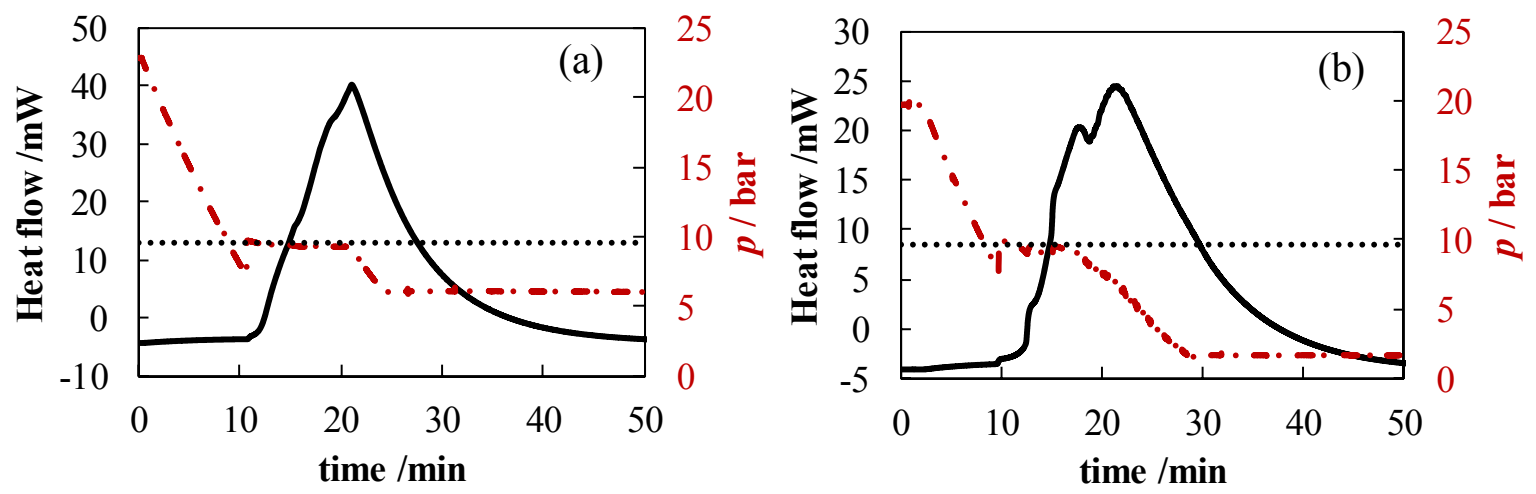

Figure 9. Thermograms obtained during expansion at $0.02 \mathrm{~cm}^{3} / \mathrm{min}$ and $162.9^{\circ} \mathrm{C}$ of (a) n-hexane and (b) n-hexane overfilled in silica gel. Heat flow (solid line), pressure (dashed-dotted line) and saturation pressure reported by NIST (Lemmon et al. 2013) (dotted line).

\section{Conclusions}

An experimental study of the vapor-liquid equilibria of n-hexane, n-octane and n-decane confined in different porous materials was carried out. The characterization of the porous materials was performed, showing that the synthetic porous materials have average pore diameters of 5.85 and $12.66 \mathrm{~nm}$, whereas the studied reservoir rock samples from the Ekofisk and the Tuxen formations have a very similar pore size distribution with an average pore diameter around $400 \mathrm{~nm}$.

Despite the fact that the Tuxen formation in the Valdemar field is very tight, the chalk sample analyzed has a pore size similar to the one from the Ekofisk formation in the Gorm field. The degree of confinement of these chalk rocks was not enough to produce a measurable shift of the vapor-liquid equilibrium of the confined n-octane and n-decane compared to the bulk fluids.

On the other hand, the degree of confinement of the synthetic porous materials is high enough to create a shift in the vapor-liquid equilibrium of the confined fluids, the boiling points of n-octane and n-decane were shifted to higher temperatures, a shift around 13 and $20^{\circ} \mathrm{C}$ was measured for the fluids confined in silica gel $(12.66 \mathrm{~nm})$ and SBA-15 $(5.85 \mathrm{~nm})$, respectively. The temperature shift predicted by the model was around 8 and $15^{\circ} \mathrm{C}$, respectively. A reasonable agreement of the experimental results with measurements previously published by other researchers was found.

The study of n-hexane confined in silica gel at pressures up to 29 bar resulted in the observation of a distinct bubble point for the bulk and confined fluid, suggesting effects other than capillary pressure may play a role. Further investigations are required in order to elucidate the influence of pressure in the temperature shift. It should be reflected whether some dynamic effects in the calorimetry approach may influence the obtained thermograms.

\section{Acknowledgements}

The authors thank Prof. Søren Kegnæs, John C. Troelsen and Ditte Jul Valentin for the help with the nitrogen sorption and mercury intrusion porosimetry determinations. The authors are grateful to the Danish Hydrocarbon Research and Technology Centre for their financial support and technical collaboration. 


\section{Nomenclature}

$\begin{array}{ll}\rho & \text { density } \\ \sigma & \text { interfacial tension } \\ \theta & \text { fluid-wall contact angle } \\ \chi & \text { parachor constant } \\ \omega & \text { accentric factor } \\ & \\ d & \text { pore diameter } \\ D V(d) & \text { pore volume change w.r.tpore diameter } \\ f & \text { fugacity } \\ J & \text { Jacobian } \\ p & \text { pressure } \\ p_{\text {cap }} & \text { capillary pressure } \\ p_{c} & \text { critical pressure } \\ p^{g} & \text { gas pressure } \\ p^{l} & \text { liquid pressure } \\ p_{0} & \text { reference pressure for nitrogen sorption isotherms (1 bar) } \\ r_{c} & \text { capillary radius } \\ T & \text { temperature } \\ \Delta T & \text { temperature change } \\ T_{c} & \text { critical temperature } \\ T_{\mathrm{onset}} & \text { onset temperature } \\ T_{\mathrm{ref}} & \text { reference temperature } \\ V & \text { pore volume }\end{array}$

\section{References}

Barrett, E. P., Joyner, L. G., and Halenda, P. P. 1951. The Determination of Pore Volume and Area Distributions in Porous Substances. I. Computations from Nitrogen Isotherms. J. Am. Chem. Soc. 73 (1): 373-380. https://doi.org/10.1021/ja01145a126.

Brunauer, S., Emmett, P. H., and Teller, E. 1938. Adsorption of Gases in Multimolecular Layers. J. Am. Chem. Soc. 60 (2): 309-319. https://doi.org/10.1021/ja01269a023.

Cho, H., Caputo, D., Bartl, M. H., and Deo, M. 2018. Measurements of Hydrocarbon Bubble Points in Synthesized Mesoporous Siliceous Monoliths. Chem. Eng. Sci. 177: 481-490. https://doi.org/10.1016/j.ces.2017.12.005.

Dong, X., Liu, H., Hou, J., Wu, K., and Chen, Z. 2016. Phase Equilibria of Confined Fluids in Nanopores of Tight and Shale Rocks Considering the Effect of Capillary Pressure and Adsorption Film. Ind. Eng. Chem. Res. 55 (3): 798-811. https://doi.org/10.1021/acs.iecr.5b04276.

Firincioglu, T., Ozkan, E., and Ozgen, C. 2012. Thermodynamics of Multiphase Flow in Unconventional Liquids-Rich Reservoirs. Presented at the SPE Annual Technical Conference and Exhibition, San Antonio, Texas, USA. 2012/1/1/. https://doi.org/10.2118/159869-MS.

Jakobsen, F., Ineson, J. R., Kristensen, L., Nytoft, H. P., and Stemmerik, L. 2005. The Valdemar Field, Danish Central Graben: Field Compartmentalization and Regional Prospectivity of the Lower Cretaceous Chalk Play. Geological Society, London, Petroleum Geology Conference series 6 (1): 177-186. https://doi.org/10.1144/0060177. 
Lemmon, E. W., Huber, M. L., and McLinden, M. O. 2013. NIST Standard Reference Database 23: Reference Fluid Thermodynamic and Transport Properties-REFPROP, Version 9.1, National Institute of Standards and Technology, Standard Reference Data Program, 2013.

Lemmon, E. W. and Span, R. 2006. Short Fundamental Equations of State for 20 Industrial Fluids. $J$. Chem. Eng. Data 51 (3): 785-850. https://doi.org/10.1021/je050186n.

Luo, S., Lutkenhaus, J. L., and Nasrabadi, H. 2015. Experimental Study of Confinement Effect on Hydrocarbon Phase Behavior in Nano-Scale Porous Media Using Differential Scanning Calorimetry. Presented at the SPE Annual Technical Conference and Exhibition, Houston, Texas, USA. 2015/9/28/. https://doi.org/10.2118/175095-MS.

Luo, S., Lutkenhaus, J. L., and Nasrabadi, H. 2016a. Confinement-Induced Supercriticality and Phase Equilibria of Hydrocarbons in Nanopores. Langmuir 32 (44): 11506-11513. https://doi.org/10.1021/acs.langmuir.6b03177.

Luo, S., Lutkenhaus, J. L., and Nasrabadi, H. 2018. Use of Differential Scanning Calorimetry to Study Phase Behavior of Hydrocarbon Mixtures in Nano-Scale Porous Media. J. Pet. Sci. Eng. 163: 731-738. https://doi.org/10.1016/j.petrol.2016.12.019.

Luo, S., Lutkenhaus, J. L., and Nasrabadi, H. 2019. Experimental Study of Pore Size Distribution Effect on Phase Transitions of Hydrocarbons in Nanoporous Media. Fluid Phase Equilib. 487: 8-15. https://doi.org/10.1016/j.fluid.2018.11.026.

Luo, S., Nasrabadi, H., and Lutkenhaus, J. L. 2016b. Effect of Confinement on the Bubble Points of Hydrocarbons in Nanoporous Media. AIChE J. 62 (5): 1772-1780. https://doi.org/10.1002/aic.15154.

Pathak, M., Kweon, H., Deo, M., and Huang, H. 2017a. Kerogen Swelling and Confinement: Its implication on Fluid Thermodynamic Properties in Shales. Sci. Rep. 7 (1): 12530. https://doi.org/10.1038/s41598-017-12982-4.

Pathak, M., Kweon, H., Panja, P., Velasco, R., and Deo, M. D. 2017b. Suppression in the Bubble Points of Oils in Shales Combined Effect of Presence of Organic Matter and Confinement. Presented at the SPE Unconventional Resources Conference, Calgary, Alberta, Canada. 2017/2/15/. https://doi.org/10.2118/185080-MS.

Pathak, M., Velasco, R., Panja, P., and Deo, M. D. 2017c. Experimental Verification of Changing Bubble Points of Oils in Shales: Effect of Preferential Absorption by Kerogen and Confinement of Fluids. Presented at the SPE Annual Technical Conference and Exhibition, San Antonio, Texas, USA. 2017/10/9/. https://doi.org/10.2118/187067-MS

Regueira, T., Varzandeh, F., Stenby, E. H., and Yan, W. 2017. Heat Capacity and Joule-Thomson Coefficient of Selected N-alkanes at 0.1 and 10MPa in Broad Temperature Ranges. J. Chem. Thermodyn. 111: 250-264. https://doi.org/10.1016/j.jct.2017.03.034.

Sandoval, D. R., Yan, W., Michelsen, M. L., and Stenby, E. H. 2016. The Phase Envelope of Multicomponent Mixtures in the Presence of a Capillary Pressure Difference. Ind. Eng. Chem. Res. 55 (22): 6530-6538. https://doi.org/10.1021/acs.iecr.6b00972.

Siitsman, C. and Oja, V. 2015. Extension of the DSC Method to Measuring Vapor Pressures of Narrow Boiling Range Oil Cuts. Thermochim. Acta 622: 31-37. https://doi.org/10.1016/j.tca.2015.04.011.

Span, R. and Wagner, W. 2003. Equations of State for Technical Applications. II. Results for Nonpolar Fluids. Int. J. Thermophys. 24 (1): 41-109. https://doi.org/10.1023/A:1022310214958. 
Teklu, T. W., Alharthy, N., Kazemi, H., Yin, X., Graves, R. M., and AlSumaiti, A. M. 2014. Phase Behavior and Minimum Miscibility Pressure in Nanopores. SPE Reservoir Eval. Eng. 17 (03): 396-403. https://doi.org/10.2118/168865-PA.

Wang, L., Parsa, E., Gao, Y., Ok, J. T., Neeves, K., Yin, X., and Ozkan, E. 2014. Experimental Study and Modeling of the Effect of Nanoconfinement on Hydrocarbon Phase Behavior in Unconventional Reservoirs. Presented at the SPE Western North American and Rocky Mountain Joint Meeting, Denver, Colorado. 2014/4/17/. https://doi.org/10.2118/169581-MS. 